\title{
Caracterização e Divergência Genética de Populações de Casearia grandiflora no Cerrado Piauiense
}

\author{
Marcones Ferreira Costa ${ }^{1}$, Angela Celis de Almeida Lopes ${ }^{2}$, \\ Regina Lucia Ferreira Gomes ${ }^{2}$, Ademir Sérgio Ferreira de Araújo ${ }^{3}$, \\ Maria Imaculada Zucchi ${ }^{4}$, José Baldin Pinheiro ${ }^{5}$, Sérgio Emílio dos Santos Valente ${ }^{6}$ \\ ${ }^{1}$ Universidade Federal do Piauí - UFPI, Campus Amilcar Ferreira Sobral, Floriano/PI, Brasil \\ ${ }^{2}$ Departamento de Fitotecnia, Universidade Federal do Piauí - UFPI, Teresina/PI, Brasil \\ ${ }^{3}$ Departamento de Engenharia Agrícola e Solos, Universidade Federal do Piauí - UFPI, Teresina/PI, Brasil \\ ${ }^{4}$ Departamento de Genética, Instituto Agronômico de Campinas - IAC, Campinas/SP, Brasil \\ ${ }^{5}$ Departamento de Genética, Escola Superior de Agricultura Luiz de Queiroz, Universidade de São Paulo - USP, \\ Piracicaba/SP, Brasil \\ ${ }^{6}$ Departamento de Biologia, Universidade Federal do Piauí - UFPI, Teresina/PI, Brasil
}

\begin{abstract}
RESUMO
Casearia grandiflora (Salicaceae) é uma espécie típica do cerrado piauiense, o conhecimento da diversidade genética dessa espécie é de grande importância para estabelecimento de práticas e estratégias de conservação biológica. O presente estudo teve como objetivo caracterizar a diversidade de C. grandiflora em duas áreas de cerrado do Piauí. Foram analisados 15 descritores de natureza quantitativa, através da medição do caule, folha, fruto e semente, seguida de posterior análise multivariada (componentes principais e agrupamento). Tanto a análise de componentes principais quanto os métodos de agrupamento apresentaram semelhanças na associação das plantas, o que contribuiu para o conhecimento dos padrões de variação fenotípica e divergência da espécie, sendo que a maior variação da diversidade genética foi encontrada dentro das populações. Os resultados fornecem informações importantes, visto que na literatura descrições sobre caracterização morfológica e diversidade genética dessa espécie ainda são limitadas.
\end{abstract}

Palavras-chave: características fenotípicas, componentes principais, Salicaceae.

\section{Characterization and Genetic Divergence of Casearia grandiflora Populations in the Cerrado of Piaui State, Brazil}

\begin{abstract}
Casearia grandiflora (Salicaceae) is a species typical of the savanna of Piaui state. Knowledge about its genetic diversity is of great importance to establish practices and strategies of biological conservation. This study aimed to characterize C.grandiflora diversity in two areas of savanna. Fifteen quantitative descriptors were analyzed trough measurement of steam, leaf, fruit and seed, followed by multivariate analysis (principal component and grouping). Both principal component analysis and grouping methods showed similarities in plant association, which contribute to the knowledge on patterns of phenotypic variation and species divergence, with the greatest genetic diversity variation found within the populations. The results provide important information because descriptions of morphologic characterization and genetic diversity of this species are still limited in the specific literature.
\end{abstract}

Keywords: phenotypic characteristics, principal components, Salicaceae. 


\section{INTRODUÇÃO}

O cerrado brasileiro comporta formações florestais, savânicas e campestres totalizando 11 tipos fitofisionômicos principais. As formações florestais que compõem esse bioma são: Mata Seca e Cerradão; as savânicas são: Cerrado stricto sensu, Parque de Cerrado, Palmeiral e Vereda; e as campestres: Campo Sujo, Campo Limpo e Campo Rupestre (Ribeiro \& Walter, 2001).

Esse bioma é considerado "hotspot" para a conservação da biodiversidade mundial devido à riqueza de espécies e seu elevado grau de endemismo (Myers et al., 2000; Mittermeier et al., 2005). Estudos sugerem que cerca de $80 \%$ do cerrado brasileiro está sob algum grau de pressão antrópica (Klink \& Machado, 2005).

Se, por um lado, o cerrado destaca-se por apresentar grande diversidade de tipos de ambientes, abrigando alta diversidade de espécies endêmicas e passíveis de serem comercializadas, por outro, é o bioma brasileiro mais ameaçado de destruição (Angelo et al., 2012).

O Piauí, é o estado com a maior representatividade do cerrado na região Nordeste do Brasil, ocupa cerca de 12 milhões de hectares, dos quais 70,4\% estão em sua área de domínio e 29,6\% em sua área de transição (Matos \& Felfili, 2010). Apresenta três unidades de conservação de cerrado: Estação Ecológica de Uruçuí-Uma, Parque Nacional das Nascentes do Rio Parnaíba e Parque Nacional de Sete Cidades - PNSC.

A espécie Casearia grandiflora Camb. (Salicaceae), encontrada desde a Amazônia até o estado de São Paulo, é uma árvore comum no sub-bosque de matas do Brasil central (Machado \& Oliveira, 2000). No cerrado brasileiro, é uma espécie relativamente importante, aparecendo em diversos levantamentos fitossosiológicos dessas regiões (Guilherme et al., 1998).

Essa espécie pode ser utilizada para recuperação de áreas degradadas, pois seus frutos são comestíveis e muito procurados por aves, responsáveis por sua dispersão (Klein \& Sleumer, 1984). Suas folhas contêm teores elevados de óleos essenciais, flavonóides, saponinas, taninos, resinas e antocianosídeos e apresentam atividade antiofídica (Freitas et al., 2005).

A caracterização de plantas perenes tem sido realizada com o auxílio de uma lista de descritores botânicos e morfológicos. Em C. grandiflora, ainda não há relatos na literatura especializada sobre estudos de divergência genética através de descritores morfológicos.

Considerando a importância dessa espécie no repovoamento de áreas degradadas, o presente estudo teve como objetivo caracterizar a diversidade genética através de descritores morfológicos de duas populações de C. grandiflora, uma situada na área de conservação do Parque Nacional de Sete Cidades e a outra, no município de Cocal de Telha, mais susceptível a pressões antrópicas, e verificar se existem diferenças morfológicas acentuadas entre as plantas da unidade de conservação e as que estão localizadas na área de influência antrópica.

\section{MATERIAL E MÉTODOS}

\section{1. Área de estudo e material botânico}

O estudo foi desenvolvido dentro de duas áreas de coletas no estado do Piauí (Figura 1): o município de Cocal de Telha ( $\left.4^{\circ} 33^{\prime} 32^{\prime \prime} \mathrm{S}, 41^{\circ} 58^{\prime} 20^{\prime \prime} \mathrm{W}\right)$ e na unidade de preservação do Parque Nacional de Sete Cidades (PNSC). Foram analisadas 80 plantas de C. grandiflora, sendo que 40 foram coletadas dentro do PNSC, população 1, e nomeadas em G-1 a G-40, conforme a ordem de coleta. As outras 40 encontravam-se no município de Cocal de Telha, população 2, nomeadas de G-41 a G-80.

As plantas foram selecionadas com base na disponibilidade de frutos. Foram determinadas as coordenadas geográficas (latitude e longitude) com auxílio de GPS (Global Positioning System) e coletado material botânico em estádio reprodutivo, os quais foram identificados com base em bibliografia especializada, enviados para confirmação por especialistas e incorporados ao acervo do Herbário Graziela Barroso (TEPB) da Universidade Federal do Piauí (UFPI). Após coletados, as folhas e os frutos foram acondicionados em sacos plásticos, etiquetados e levados ao Laboratório de Sementes da Universidade Federal do Piauí, para caracterização morfológica.

\subsection{Avaliação biométrica de folha, fruto e semente}

As medições físicas de folhas, frutos e sementes foram realizadas no período de maio a junho de 2014. Os seguintes descritores foram avaliados: diâmetro 


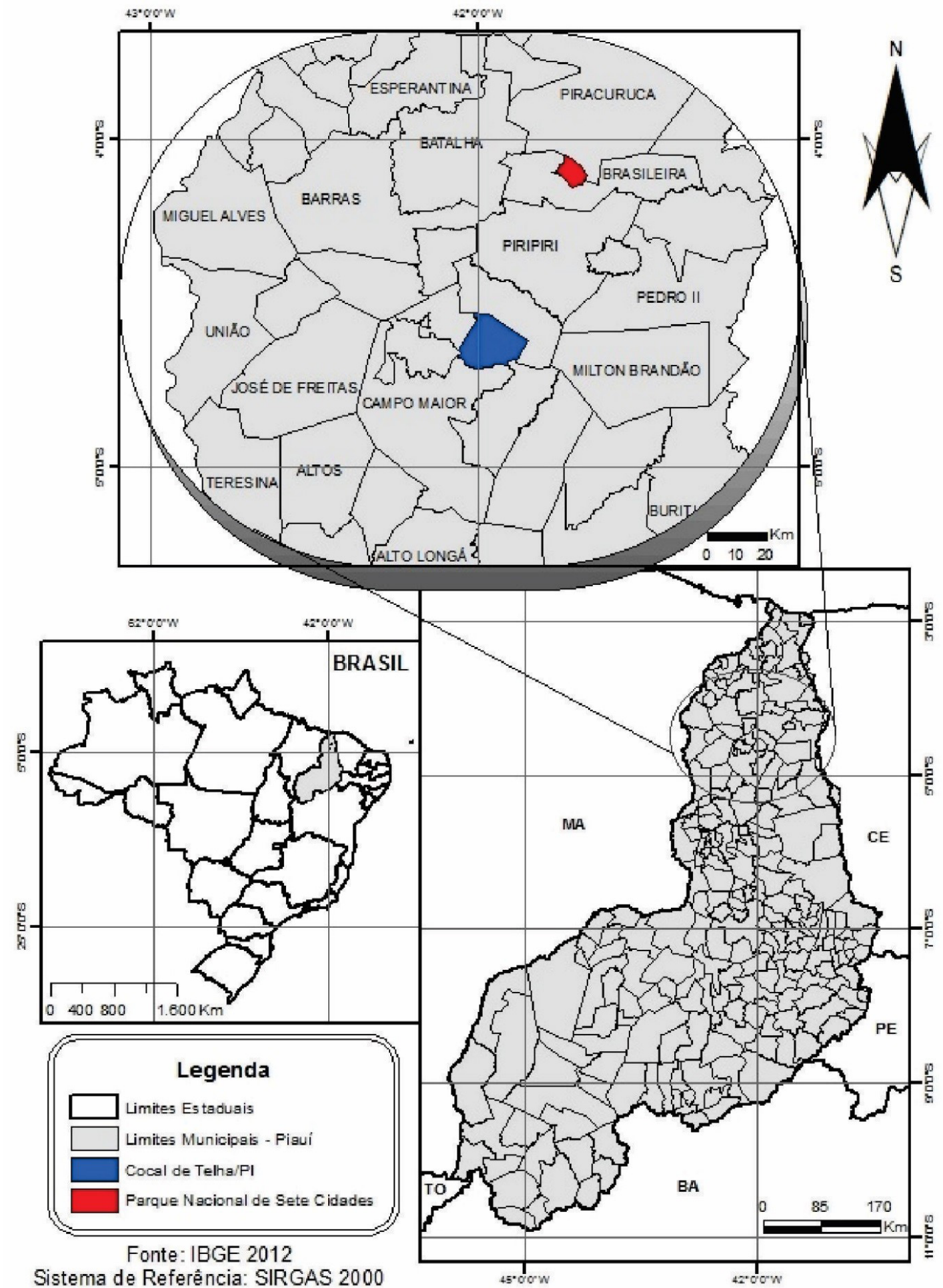

Figura 1. Localização das áreas de coleta marcadas em seus respectivos municípios.

Figure 1. Location of the collection areas marked in their respective cities. 
do caule (DAP), comprimento do pecíolo (CP), comprimento do limbo (CL), largura do limbo (LL), índice foliar (IF), peso de massa seca (PMS), peso do fruto $(\mathrm{PF})$, comprimento do fruto $(\mathrm{CF})$, largura do fruto (LF), relação comprimento/largura do fruto $(\mathrm{C} / \mathrm{LF})$, número de sementes por fruto (NS), relação comprimento/largura da semente (C/LS), peso de 100 sementes (P100S), comprimento da semente (CS) e largura da semente (LS).

As medidas de comprimento, largura, espessura e diâmetro foram realizados com o auxílio de um paquímetro digital e foram expressas em milímetros. Para as medidas de massa foi utilizada balança digital de precisão expressa em gramas. O IF foi calculado dividindo-se o comprimento do limbo por sua largura. Para efeito de medições físicas, utilizaram-se 10 medidas repetidas de folha, fruto e semente por genótipo estudado.

A diversidade genética entre os acessos foi avaliada utilizando-se métodos da ligação média entre grupos ou UPGMA (Unweighted Pair Group Method with Arithmetic Mean) e Tocher. Realizaram-se análise de componentes principais (ACP), com o intuito de eliminar as variáveis morfológicas redundantes. Os dados foram padronizados e as análises estatísticas foram processadas utilizando-se o recurso computacional Genes versão 2013.5.1, para a análise do Tocher (Cruz, 2013), e o software SAS 9.0 (SAS Institute, 2002), para as análises de UPGMA e dos componentes principais.

\section{RESULTADOS E DISCUSSÃO}

As análises morfológicas realizadas nas 80 plantas selecionadas para este estudo permitiram a sua diferenciação bem como agrupá-las de acordo com a similaridade. Com base nas análises dos descritores foliares (Tabela 1), todas as plantas apresentaram valores de índice foliar maiores que um, indicando que a espécie investe mais no crescimento longitudinal das folhas do que na largura, em resposta à adequação às condições ambientais, uma vez que essa característica está fortemente relacionada com a maximização do aproveitamento da energia luminosa.

Os valores observados para os caracteres morfológicos foliares (comprimento do pecíolo, comprimento do limbo, largura do limbo, índice foliar e peso de massa seca) nessas áreas são importantes, já que tais características variam com a distribuição espacial e temporal da espécie, disponibilidade de luz e idade da folha. As diferenças observadas entre os caracteres foliares refletem a adaptação dessa espécie ao ambiente e vale ressaltar que a folha é o órgão vegetal que responde com maior facilidade às variações ambientais (Chagas et al., 2009).

Para as duas populações estudadas, os frutos apresentaram grande variação com relação ao número de sementes em seu interior, variando de 7 a 23 sementes por fruto. A produção de grande número de sementes e a habilidade de colonizar hábitat aberto, aliadas a outros fatores, sugerem que essa espécie poderia ser uma estrategista-r, ou seja, alocam grande parte de sua energia na reprodução em detrimento da manutenção dos indivíduos (Melo et al., 2004).

A partir do número de sementes por fruto foi possível determinar o parâmetro estrategista-r, visto que esse caráter está relacionado com o processo de adaptação e história de vida da espécie, sendo possível entender que C. grandiflora distribui sua energia para os processos de crescimento e reprodução. Logo, as plantas de ambas populações alocam maior esforço energético no processo reprodutivo.

Em relação aos demais descritores fenotípicos referentes ao fruto e à semente, a população do Parque Nacional de Sete Cidades apresentou, em grande

Tabela 1. Morfometria foliar de duas populações de C. Grandiflora.

Table 1. Leaf morphometry of two populations of C. grandiflora.

\begin{tabular}{|c|c|c|c|c|}
\hline \multicolumn{5}{|c|}{ Populações } \\
\hline \multirow{2}{*}{ Descritores foliares } & \multicolumn{2}{|c|}{ Parque Nacional de Sete Cidades } & \multicolumn{2}{|c|}{ Cocal de Telha } \\
\hline & Média & Desvio & Média & Desvio \\
\hline Comprimento do pecíolo (mm) & 4,70 & 1,30 & 4,60 & 1,06 \\
\hline Comprimento do limbo (mm) & 72,76 & 15,12 & 72,25 & 13,00 \\
\hline Largura do limbo (mm) & 26,12 & 6,03 & 27,87 & 4,71 \\
\hline Índice foliar (mm) & 2,85 & 0,55 & 2,62 & 0,42 \\
\hline Peso de massa seca (g) & 1,80 & 0,60 & 4,66 & 0,97 \\
\hline
\end{tabular}


parte, as maiores médias para os caracteres analisados (Tabela 2).

Considerando-se que C. grandiflora possa a ser uma estrategista-r, espera-se que apresente estratégias adaptativas a hábitat imprevisível, o qual pode sofrer algum tipo de perturbação, como é o caso da região de Cocal de Telha. Dessa forma, essa planta pode ocupar ambientes antropizados, o que permite que possa ser utilizada em projetos de restauração.

Imatomi et al. (2009) realizaram a caracterização morfológica de $C$. sylvestris e obtiveram os seguintes valores médios $0,05,5,40,4,45$ e 1,96 para as variáveis peso do fruto $(\mathrm{g})$, comprimento do fruto $(\mathrm{mm})$, largura do fruto ( $\mathrm{mm}$ ) e peso de 1000 sementes (g), respectivamente. Haliski et al. (2013) encontraram os valores médios 4,02, 3,28 $\mathrm{mm}$ respectivamente, para os descritores comprimento e largura da semente em Casearia decandra.

Os resultados encontrados por ambos trabalhos referenciados acima apresentam similaridade com os resultados de mensurações observados na caracterização de fruto e semente das duas populações de C. grandiflora no presente estudo, como pode ser observado na Tabela 2

A variação observada entre número e tamanho das sementes são informações importantes, uma vez que elas estão diretamente relacionadas com a germinação e o vigor da espécie, o que repercute no estabelecimento da planta no ambiente, além de influenciar na distribuição e dinâmica da população (Rosa \& Ferreira, 2001).

O método de agrupamento de Tocher foi eficiente na discriminação dos indivíduos geneticamente, permitindo agrupá-los de forma tal que há homogeneidade dentro do grupo e heterogeneidade entre os grupos. Essa análise reuniu os genótipos das duas populações em seis grupos distintos (Tabela 3).

O grupo I reuniu o maior número de genótipos $(87,5 \%)$. Todas as plantas da população de Cocal de Telha concentram-se nesse grupo, além de $75 \%$ da população do Parque Nacional de Sete Cidades. Os grupos II, III, IV, V e VI são constituídos apenas por representantes do Parque, sendo que os grupos III e IV são formados por dois genótipos e os grupos V e VI apresentam um único representante.

Pelas distâncias intergrupos foi constada maior dissimilaridade genética entre os grupos V e VI $(0,57)$ (Tabela 4). Como concentram indivíduos pertencentes à população do Parque Nacional de Sete Cidades, os genótipos mais divergentes estão presentes nessa unidade de conservação.

A interpretação do método de Tocher indica maior variabilidade genética dentro das populações de C. grandiflora, com pouca diferenciação entre as populações, uma vez que a maioria dos indivíduos do Parque Nacional de Sete Cidades estão agrupados juntos com os de Cocal de Telha.

A baixa diferenciação genética entre as populações pode estar relacionada à biologia reprodutiva da espécie, a qual apresenta uma taxa de polinização cruzada acima de 95\% (alógama), portanto, essa espécie mantém a maior parte da sua variação genética dentro das suas populações, ao invés de entre elas.

No agrupamento pelo método UPGMA (Figura 2), observa-se a formação de seis grupos, a mesma

Tabela 2. Caracterização morfológica de frutos e sementes das populações C. grandiflora analisadas.

Table 2. Morphological characterization of fruits and seeds of C. grandiflora populations analyzed.

\begin{tabular}{|c|c|c|c|c|}
\hline \multirow{2}{*}{ Descritores } & \multicolumn{2}{|c|}{ Parque Nacional de Sete Cidades } & \multicolumn{2}{|c|}{ Cocal de Telha } \\
\hline & Média & Desvio & Média & Desvio \\
\hline Peso do fruto (g) & 0,06 & 0,02 & 0,06 & 0,02 \\
\hline Comprimento do fruto (mm) & 6,00 & 0,75 & 6,30 & 0,48 \\
\hline Largura do fruto $(\mathrm{mm})$ & 3,83 & 0,52 & 4,50 & 0,38 \\
\hline $\begin{array}{l}\text { Relação comprimento e largura } \\
\text { do fruto }(\mathrm{mm})\end{array}$ & 1,60 & 0,14 & 1,41 & 0,10 \\
\hline Número de sementes & 12,9 & 1,08 & 11,71 & 0,83 \\
\hline Comprimento da semente ( $\mathrm{mm})$ & 2,05 & 0,35 & 2,30 & 0,21 \\
\hline Largura da semente $(\mathrm{mm})$ & 1,18 & 0,28 & 1,30 & 0,11 \\
\hline $\begin{array}{l}\text { Relação comprimento e largura } \\
\text { da semente }(\mathrm{mm})\end{array}$ & 1,86 & 0,29 & 1,72 & 0,12 \\
\hline Peso de 100 sementes $(\mathrm{g})$ & 0,15 & 0,15 & 0,08 & 0,11 \\
\hline
\end{tabular}


Tabela 3. Agrupamento dos genótipos das duas populações de C. grandiflora coletadas no Parque Nacional de Sete Cidades (G-1 a G-40) e Cocal de Telha (G-41 a G-80), com base em 15 descritores morfológicos, pelo método de Tocher.

Table 3. Grouping the genotypes of the two populations of C. grandiflora collected in Parque Nacional de Sete Cidades (G-1 to G-40) and Cocal de Telha (G-41 to G-80), based on morphological descriptors 15, by the method of Tocher.

\section{Grupo Genótipos}

G-48, G-73, G-76, G-65, G-56, G-55, G-78, G-51, G-80, G-71, G-69, G-64, G-66, G-49, G-50, G-58, G-57, G-62, G-72, G-70, G-47, G-60, G- 46, G-68, G- 67, G-79, G-44,

I G-63, G-59, G-77, G-53. G-54, G-52, G-45, G-74, G-7,

Parque Nacional de Sete Cidades + Cocal de Telha G-61, G-41, G-43, G-1, G-75, G-39, G- 42, G-23, G-20, G-19, G-28, G-38, G-29, G-30, G-6, G-18, G-5, G-33, G-35, G-32, G-2, G-27, G-37, G-25, G- 4 G- 8, G-12, G-17, G-34, G-10, G- 26, G-31, G-36, G-3.

$\begin{array}{ll}\text { II } & \text { G-16, G-40, G-14, G-15 } \\ \text { Parque Nacional de Sete Cidades } & \text { G-9, G-11 } \\ \begin{array}{l}\text { III } \\ \text { Parque Nacional de Sete Cidades }\end{array} & \text { G-22, G-24 } \\ \begin{array}{l}\text { IV } \\ \text { Parque Nacional de Sete Cidades }\end{array} & \text { G-21 } \\ \begin{array}{l}\text { V } \\ \text { Parque Nacional de Sete Cidades }\end{array} & \text { G-13 } \\ \begin{array}{l}\text { VI } \\ \text { Parque Nacional de Sete Cidades }\end{array}\end{array}$

Tabela 4. Distância inter e intragrupos pelo método de Tocher de duas populações de C. grandiflora coletadas no cerrado piauiense com base em caracteres morfológicos.

Table 4. Distance between and within groups by Tocher method of two populations of C. grandiflora collected in Piauí Cerrado based on morphological characters.

\begin{tabular}{cccccc}
\hline & I & II & III & IV & V \\
\hline I & 0,24 & & & & \\
II & 0,33 & 0,24 & & & \\
III & 0,38 & 0,36 & 0,23 & 0,26 & \\
IV & 0,30 & 0.34 & 0,43 & 0,32 & 0,57 \\
\hline V & 0,33 & 0,43 & 0,49 & 0,49 & \\
VI & 0,48 & 0,33 & 0,35 & & \\
\hline
\end{tabular}

quantidade observada no método de otimização de Tocher (Tabela 3). O sexto grupo do método de Tocher é constituído apenas pelo genótipo G-13, que pela análise UPGMA pertence ao grupo II. Esse grupo, por sua vez, reúne $17,5 \%$ dos indivíduos do Parque Nacional de Sete Cidades e 21,25\% dos de Cocal de Telha, agrupando a maior parte dos genótipos de ambas populações.

Os grupos I, III, IV e V reúnem respectivamente $17,5 \%, 11,25 \%, 1,25 \%$ e 3,75\% dos genótipos do Parque Nacional de Sete Cidades e 16,25\%, 7,5\%, 1,25\% e $2,5 \%$, respectivamente, dos genótipos de Cocal de Telha. Dessa forma, todos os grupos formados a partir do método UPGMA reuniram genótipos das duas populações, o que fortalece a proximidade genética entre elas e uma possível complementariedade entre os genótipos.

O desempenho da análise do agrupamento, com base em descritores morfológicos, foi revelado através do coeficiente de correlação cofenética (ccc). Segundo Rohlf (1970), valores de correlação cofenética menores que 0,70 indicam inadequação do método de agrupamento. No presente estudo a correlação cofenética do dendrograma foi igual a 0,73 , o que indica que o método de UPGMA foi adequado no agrupamento dos genótipos. 


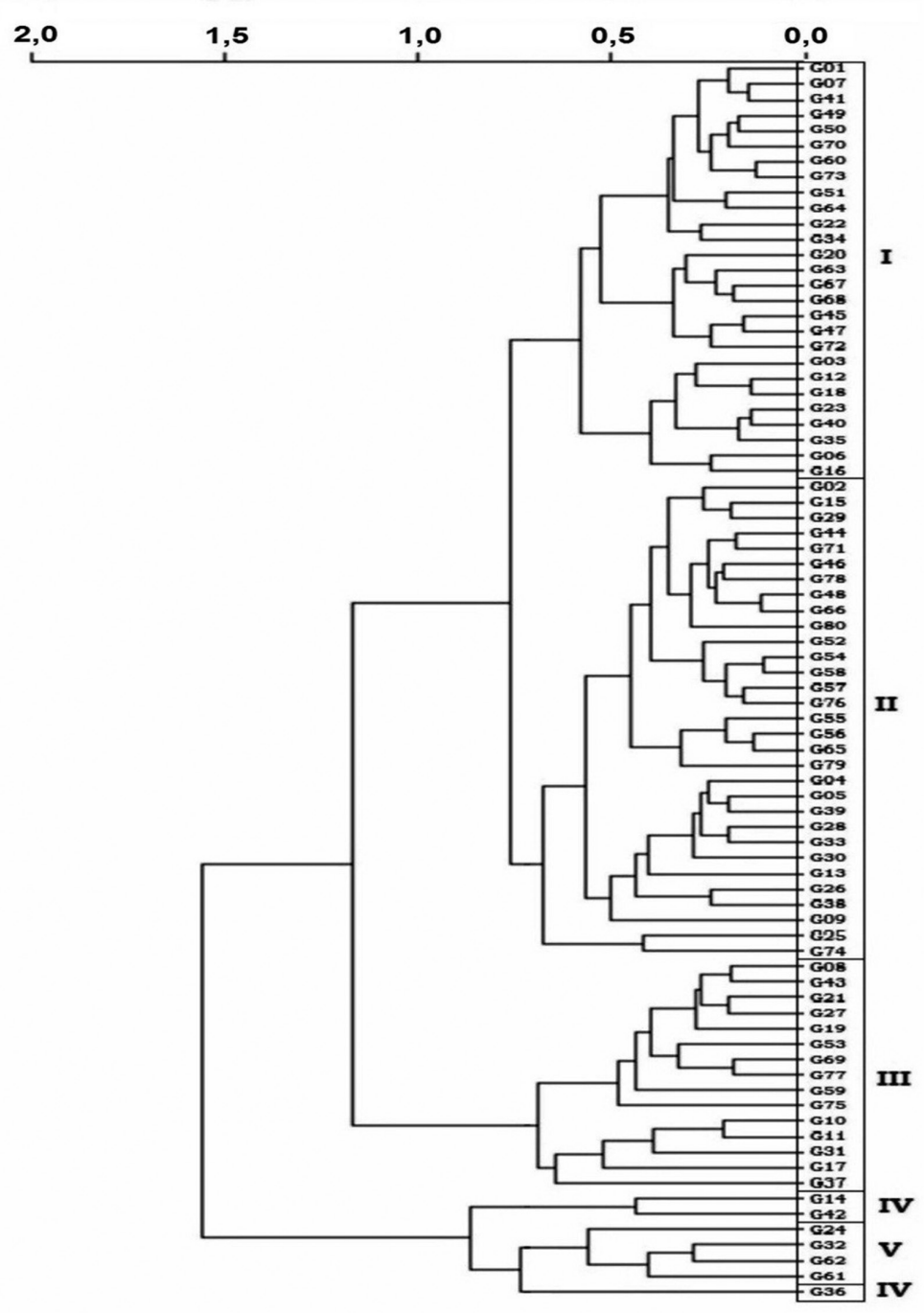

Figura 2. Dendrograma resultante da análise multivariada em duas populações de C. grandiflora pelo método de agrupamento UPGMA.

Figure 2. Dendrogram result of multivariate analysis in two populations of $C$. grandiflora, the UPGMA clustering method.

O principal objetivo da análise de componentes principais é revelar as tendências na variação dos genótipos dentro de todo o conjunto de dados analisados. A partir das médias dos 15 descritores morfológicos foram fornecidos valores para variância, porcentagem da variância e variância acumulada de cada componente principal (Tabela 5).

O primeiro componente principal respondeu por $31,57 \%$ da variação total, enquanto os dois primeiros componentes acumularam 42,09\% da variância total. De acordo com o critério de Kaiser (1960), selecionaram-se os cinco primeiros componentes principais, já que foram obtidos autovalores superiores a 1,0. Esses componentes principais explicaram 74,58\% da variação. Cruz et al. (2011) relatam que o ideal é que os dois primeiros componentes principais concentrem a maior quantidade de variância dos dados para que haja divergência entre grupos de genótipos.

Há estudos em que a análise tem se mostrado eficaz na avaliação da diversidade genética, mesmo quando esse limite não é atingido. Vieira et al. (2014), ao utilizarem o método de componentes principais para revelar as principais tendências de variações da forma da folha de duas espécies do gênero Anacardium, 
indicaram que 11 descritores são necessários para expressar mais de $80 \%$ da variação e, mesmo assim, os escores desses componentes possibilitaram distinguir os grupos das variáveis.

Os caracteres que mais contribuíram para a variabilidade do componente principal 1 foram a largura da semente, relação comprimento e largura do fruto, largura do fruto, número de sementes por fruto e comprimento da semente, que foram reunidos no grupo denominado estruturas reprodutivas da planta. No componente principal 2, os componentes que mais contribuíram para variabilidade foram comprimento do pecíolo, relação comprimento e largura do fruto e número de sementes por fruto, que representam os componentes morfométricos de folhas e frutos.

No gráfico biplot (Figura 3) no qual foram plotados os componentes principais 1 e 2 , é possível perceber que o genótipo G-13 é o mais divergente em relação

Tabela 5. Estimativa dos autovalores associados aos componentes principais e sua variância percentual e acumulada dos 15 caracteres morfológicos em C. Grandiflora.

Table 5. Estimates of the eigenvalues associated to the main components and their percentage and cumulative variance of 15 morphological characters in C. grandiflora.

\begin{tabular}{|cccc|}
\hline Componente & Autovalor & Variância (\%) & Variância acumulada \\
\hline 1 & 4,74 & 31,57 & 31,57 \\
\hline 2 & 2,06 & 13,71 & 45,28 \\
\hline 3 & 1,76 & 11,71 & 56,98 \\
\hline 4 & 1,49 & 9,925 & 66,91 \\
\hline 5 & 1,15 & 7,67 & 74,58 \\
\hline 6 & 0,921 & 6,14 & 80,72 \\
\hline 8 & 0,782 & 5,21 & 85,93 \\
\hline 9 & 0,716 & 4,77 & 90,70 \\
\hline 10 & 0,529 & 3,52 & 94,23 \\
\hline 11 & 0,442 & 2,94 & 97,17 \\
\hline 12 & 0,368 & 2,45 & 99,62 \\
\hline 13 & 0,021 & 0,14 & 99,76 \\
\hline 15 & 0,019 & 0,13 & 99,89 \\
\hline
\end{tabular}

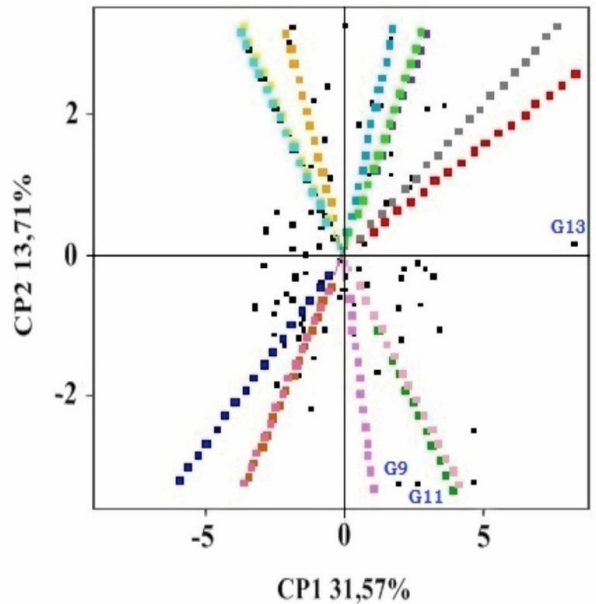

\begin{tabular}{|c|c|c|}
\hline VARIÁVEL & EIXO BIPLOT & LINHA REF \\
\hline DAP & & ............ \\
\hline CP & & 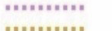 \\
\hline CL & & ............. \\
\hline IF & & n........... \\
\hline PF & & "............ \\
\hline PMS & - & "..........." \\
\hline $\begin{array}{l}C F \\
\text { LF }\end{array}$ & 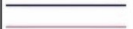 & ".........". \\
\hline CLF & & ........... \\
\hline NSF & & ............. \\
\hline LS & & nowerese \\
\hline CS & & " \\
\hline $\begin{array}{l}\text { CLS } \\
\text { PS }\end{array}$ & & 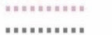 \\
\hline
\end{tabular}

Figura 3. Gráfico biplot entre os dois primeiros componentes principais para os 15 descritores avaliados em duas populações de C. Grandiflora.

Figure 3. Graphic biplot between the first two principal components for the fifteen descriptors evaluated in two populations of C. grandiflora. 
aos demais indivíduos. Pelo método de Tocher, esse genótipo não foi agrupado com nenhum outro, sendo o único representante do grupo VI.

Para os genótipos G-9 e G-11 é possível observar, por meio do gráfico, que estão próximos e apresentam uma correlação entre as características peso do fruto, largura da semente, relação comprimento e largura da semente e índice foliar. Pelo método de Tocher esses genótipos constituem o grupo III (Tabela 3). Tanto o gráfico biplot quanto o método de agrupamento de Tocher apresentaram semelhanças na associação de alguns genótipos, por exemplo G-13-G-9 e G-11-G-22 e G-24.

\section{CONCLUSÃO}

A caracterização morfológica de C. grandiflora permitiu conhecer quais os descritores que mais contribuem para a divergência genética e forneceu subsídios para o conhecimento dos padrões de variação fenotípica das duas populações, sendo que maior parte da variação genética está localizada dentro das populações.

Dessa forma, esses resultados fornecem informações importantes para a taxonomia e conservação da espécie, já que na literatura as informações sobre descrições das características morfológicas dessa espécie são limitadas, sendo o presente trabalho pioneiro para caracterização fenotípica de populações naturais de C. grandiflora. Entretanto há a necessidade de um acúmulo maior de informações, principalmente através de estudos moleculares, para poder apontar direções mais sustentáveis para o manejo, compreensão da dinâmica da espécie e desenvolvimento de estratégias conservacionistas.

\section{AGRADECIMENTOS}

Os autores agradecem à FAPEPI (Fundação de Amparo à pesquisa do Piauí) pelo auxílio financeiro através do PRONEX (FAPEPI/CNPq).

\section{STATUS DA SUBMISSÃO}

Recebido: 27 jan., 2016

Aceito: 2 fev., 2016

\section{AUTOR(ES) PARA CORRESPONDÊNCIA}

\section{Marcones Ferreira Costa}

Universidade Federal do Piauí - UFPI, Campus Amilcar Ferreira Sobral, BR 343, Km 3,5, Bairro Meladão, CEP 64800-000, Floriano, PI, Brasil e-mail: marconesbiologo@hotmail.com, marconescosta@ufpi.edu.br

\section{REFERÊNCIAS}

Angelo H, Pompamayer RS, Viana MC, Almeida AN, Moreira JMMAP, Souza NA. Valoração econômica da depredação do Pequi (Caryocar brasiliense Camb.) no Cerrado brasileiro. Revista Scientia Forestalis 2012; 40: 035-045.

Chagas MGS, Silva MD, Galvíncio DJ, Pimentel RMM. Variações foliares em grupos funcionais vegetais de uma paisagem de Restinga, Pernambuco-Brasil. Revista Brasileira de Geografia Física 2009; 2: 50-63.

Cruz CD, Ferreira FM, Pessoni LA. Biometria aplicada ao estudo da diversidade genética. Minas Gerais: Suprema Gráfica Editora; 2011.

Cruz CD. Programa genes: aplicativo computacional em genética e estatística [online]. Viçosa: UFV; 2013. [cited 2013 Maio 13]. Available from: http://www.ufv.br/dbg/ genes/genes.htm.

Freitas FG, Silva TA, Oliveira F, Santos BR, HomsiBrandeburgo MI. Toxidade aguda e propriedades antiofídicas do extrato aquoso de Casearia grandiflora (Flacourtiaceae): Atividades fosfolopásica $\mathrm{A}_{2}$, miotóxica e letal de peçonhas de B. moojeni e B. Neuwiedi. Bioscience Journal 2005; 21: 95-103.

Guilherme FG, Nakajima JN, Prado-Lima CA, Vanini A. As fitofisionomias e a flora lenhosa nativa do Parque do Sabiá, Uberlândia- MG. Daphne 1998; 8: 17-30.

Haliski S, Cosmo LN, Gogosz AM, Rego SS, Nogueira AC, Kuniyoshi YS. Caracterização morfológica de frutos, sementes, plântulas e germinação de sementes de Casearia decandra. Pesquisa Florestal Brasileira 2013; 75(75): 253259. http://dx.doi.org/10.4336/2013.pfb.33.75.451.

Imatomi M, Perez SCJGA, Ferreira AG. Caracterização e comportamento germinativo de sementes de Casearia sylvestris swartz (Salicaceae). Revista Brasileira de Sementes 2009; 31(2): 36-47. http://dx.doi.org/10.1590/S010131222009000200004 .

Kaiser HF. The application of electronic computers to factor analysis. Educational and Psychological Measurement 1960; 20(1): 141-151. http://dx.doi. org/10.1177/001316446002000116.

Klein RM, Sleumer HO. Flacourtiaceae. In: Reitz PR. Flora ilustrada catarinense. Itajaí: Herbário Barbosa Rodrigues; 1984. p. 1-95. 
Klink CA, Machado R. Conservation of the Brazilian Cerrado. Conservation Biology 2005; 19(3): 707-713. http:// dx.doi.org/10.1111/j.1523-1739.2005.00702.x.

Machado AO, Oliveira PEAM. Biologia floral e reprodutiva de Casearia grandiflora Camb. (Flacourtiaceae). Revista Brasileira de Botanica. Brazilian Journal of Botany 2000; 23(3): 283-290. http://dx.doi.org/10.1590/S010084042000000300004 .

Matos MQ, Felfili JM. Florística, fitossociologia e diversidade da vegetação arbórea nas matas de galeria do Parque Nacional de Sete Cidades (PNSC), Piauí, Brasil. Acta Botanica Brasílica 2010; 24(2): 483-496. http://dx.doi. org/10.1590/S0102-33062010000200019.

Melo FPL, Aguiar Neto AV, Simabukuro EA, Tabarelli M. Recrutamento e estabelecimento de plântulas. In: Ferreira AG, Borghetti F. Germinação: do básico ao aplicado. São Paulo: Artmed; 2004. p. 237-250.

Mittermeier RA, Gil RP, Hoffman M, Pilgrim J, Brooks TM, Mittermeier CG et al. Hotspots revisited: earth's biologically richest and most endangered terrestrial ecoregions. Boston: Cemex; 2005.
Myers N, Mittermeier RA, Mittermeier CG, Fonseca GA, Kent J. Biodiversity hotspots for conservation priorities. Nature 2000; 403(6772): 853-858. http://dx.doi. org/10.1038/35002501. PMid:10706275

Ribeiro RF, Walter BMT. Cerrado e caracterização e recuperação de Matas de Galeria. Planaltina: Embrapa Cerrados; 2001. p. 29-47.

Rohlf, FJ. Adaptative hierarchical clustering schemes. Systematic zoological 1970; 19: 58-82.

Rosa SGT, Ferreira AG. Germinação de sementes de plantas medicinais Lenhosas. Acta Botanica Brasílica 2001; 15(2): 147-154. http://dx.doi.org/10.1590/S010233062001000200001 .

SAS Institute. SAS language and procedures: usage. Version 9.0. [CD-ROM]. Cary: SAS Institute; 2002.

Vieira M, Mayo SJ, Andrade IM. Geometric morphometrics of leaves of Anacardium microcarpum Ducke and A. occidentale L. (Anacardiaceae) from the coastal region of Piauí, Brazil. Brazilian Journal of Botany 2014; 37(3): 315-327. http://dx.doi.org/10.1007/s40415-014-0072-3. 